\title{
Preparation, Structural Features and in vitro Immunostimulatory Activity of a Glucomannan From Fresh Dendrobium catenatum Stems
}

\author{
Jingjing Liu ${ }^{1 \dagger}$, Luyao $\mathrm{Yu}^{2 \dagger}$, Chun Wang ${ }^{3}$, Yuefan Zhang ${ }^{4}$, Hangxian $\mathrm{Xi}^{1}$, Jinping $\mathrm{Si}^{1}$, \\ Lei Zhang ${ }^{1,2,4 *}$ and Jingkun Yan ${ }^{3 *}$ \\ ${ }^{1}$ State Key Laboratory of Subtropical Silviculture, Zhejiang A\&F University, Hangzhou, China, ${ }^{2}$ Department of Pharmaceutical \\ Botany, School of Pharmacy, Second Military Medical University, Shanghai, China, ${ }^{3}$ Key Laboratory of Healthy Food \\ Development and Nutrition Regulation of China National Light Industry, School of Chemical Engineering and Energy \\ Technology, Dongguan University of Technology, Dongguan, China, ${ }^{4}$ Biomedical Innovation R\&D Center, School of Medicine, \\ Shanghai University, Shanghai, China
}

OPEN ACCESS

Edited by:

Ren-You Gan,

Chinese Academy of Agricultural

Sciences, China

Reviewed by:

Henan Zhang,

Shanghai Academy of Agricultural

Sciences, China

Baojun Xu,

United International College, China

Ding-Tao Wu,

Chengdu University, China

*Correspondence:

Lei Zhang

zhanglei@smmu.edu.cn

Jingkun Yan

yanjk@dgut.edu.cn;

jkyan_27@163.com

tThese authors have contributed equally to this work

Specialty section:

This article was submitted to Nutrition and Food Science

Technology,

a section of the journal

Frontiers in Nutrition

Received: 28 November 2021 Accepted: 30 December 2021

Published: 01 February 2022

Citation:

Liu J, Yu L, Wang C, Zhang Y, Xi H,

Si J, Zhang $L$ and Yan J (2022)

Preparation, Structural Features and in vitro Immunostimulatory Activity of a Glucomannan From Fresh Dendrobium catenatum Stems. Front. Nutr. 8:823803. doi: 10.3389/fnut.2021.823803
Dendrobium catenatum polysaccharides (DCPs) have attracted attention due to their multiple physiological activities and health benefits. In this study, a novel water-soluble DCP was obtained from fresh $D$. catenatum stems through three-phase partitioning and ethanol precipitation at room temperature. Its structural characteristics, rheological property, and in vitro immunostimulatory activity were evaluated. Results demonstrated that DCP was a homogenous polysaccharide with a carbohydrate content of $92.75 \%$ and a weight-average molecular weight of $2.21 \times 10^{5} \mathrm{Da}$. This polysaccharide is an O-acetylated glucomannan comprised by glucose, mannose, and galacturonic acid in a molar ratio of 30.2:69.5:0.3 and mainly comprises ( $1 \rightarrow 4)-\beta-D-m a n n o p y r a n o s y l ~(M a n p)$, 2 -O-acetyl-( $1 \rightarrow 4)-\beta$-D-Manp, ( $1 \rightarrow 6)$ - $\alpha$-D-glucopyranosyl (Glcp), and ( $1 \rightarrow 4)-\alpha$-D-Glcp residues. DCP exhibits an extended rigid chain in an aqueous solution and favorable steady shear fluid and dynamic viscoelastic behaviors. In vitro immunostimulating assays indicated that DCP activates RAW264.7 cells, thus markedly promoting macrophage proliferation and phagocytosis and increasing the levels of nitric oxide, interferon- $\gamma$, interleukin-6, and interleukin-1 $\beta$. Moreover, the presence of $O$-acetyl group and high $M_{w}$ in DCP might be responsible for its potent immunostimulatory activity in vitro. Therefore, our data suggested that DCP could be developed as a promising immunostimulant in functional food and pharmaceutical industries.

Keywords: Dendrobium catenatum, polysaccharide, three-phase partitioning, structure, rheological property, immunostimulatory activity

\section{INTRODUCTION}

Dendrobium catenatum Lindley (D. catenatum), generally called Tie-Pi-Shi-Hu in Chinese, is a perennial epiphytic herb belonging to Orchidaceae family (1). As a valuable traditional Chinese medicine, $D$. catenatum is commonly consumed as a tonic and a precious food therapy for several thousand years in China according to the ancient Chinese medical book "Shennon G's Materia Medica" (2). This herb has been named as "the gold in medicine" and "the life-saving fairy grass" 
by the people because it benefits the stomach, nourishes Yin, clears heat, moistens the lungs, and relieves cough (3). Modern pharmacological studies showed that $D$. catenatum exhibits immuno-strengthening, anti-fatigue, antioxidant, promoting digestion, hypoglycemic, and antihypertensive effects (4). These multiple physiological activities and health benefits are attributed to its many bioactive components, including polysaccharides, amino acids, sesquiterpenoids, and alkaloids. As a high quality dietary food, D. catenatum has also been extensively applied in porridges, soups, and vegetables and is officially authorized by the China Food and Drug Administration (5).

D. catenatum polysaccharides (DCPs) are one of the most important bioactive compounds in D. catenatum and exhibit a wide spectrum of biological activities, such as immunostimulation (6), anti-tumor (7), antioxidation (8), antidiabetes (9), anti-inflammation (10), hepatoprotection (11), cardioprotection (12), and beneficial effects on intestinal microbiota $(10,13)$. Over the last 2 decades, many DCPs with diverse structures and biological activities have been extracted and isolated from the stems, leaves, and flowers of D. catenatum by using different extraction techniques (14-16). Most of these DCPs are classified as 1,4-linked glucomannan or mannoglucan, and their $\beta$-configurations are acetylated to varying degrees and locations, with or without branching. $D$. catenatum plant must be dried prior to DCP extraction, but this step increases equipment input and maintenance costs and may affect the physiological activities of DCPs. Existing extraction and separation protocols are often associated with disadvantages of high temperature, laborious work, and low efficiency. Three-phase partitioning (TPP), which typically involves $t$-butanol and $\left(\mathrm{NH}_{4}\right)_{2} \mathrm{SO}_{4}$, has been extensively applied for the extraction and separation of active ingredients including proteins, enzymes, lipids, polysaccharides, and small-molecular organic compounds (17). In our research, bioactive polysaccharides have been extracted and isolated from fresh okra pods and garlic bulbs by using TPP coupled with non-solvent gradient precipitation methods $(18,19)$. To our knowledge, no or only a few investigations have focused on the production, structural features, and biological activities of DCPs extracted from fresh D. catenatum stems through TPP.

In this work, a novel DCP was extracted and separated from fresh $D$. catenatum stems via TPP coupled with ethanol precipitation. Its physiochemical, structural, and rheological characteristics were investigated. In vitro immunostimulating activity on RAW264.7 macrophage cells of this DCP was also evaluated. This research provides a theoretical reference for the efficient extraction of DCPs with high purity and bioactivity from fresh $D$. catenatum stems.

\section{EXPERIMENTAL}

\section{Materials and Chemicals}

D. catenatum was harvested from the standard greenhouse located in Lin'an District, Hangzhou, Zhejiang province, China (1). Its absolute location is east longitude, $119^{\circ} 26^{\prime} 11^{\prime \prime}$; north latitude, $30^{\circ} 20^{\prime} 30^{\prime \prime}$; altitude, $280 \mathrm{~m}$. The original $D$. catenatum plant was cultivated in a substrate of pine barks, and the stem with moisture content of 76.15\% was collected in December 2019. The botanical origin of plant was identified by Professor Jinpin $\mathrm{Si}$ from Zhejiang A\&F University (Hangzhou, China).

Trifluoroacetic acid (TFA), bovine serum albumin (BSA), deuterium oxide $\left(\mathrm{D}_{2} \mathrm{O}, 99.9 \%\right)$, lipopolysaccharides (LPS), sulfanilamide, and $\mathrm{N}$-(1-napthyl) ethylenodiamine hydrochloride were supplied by Sigma-Aldrich (St. Louis, MO, USA). Cytokine detecting ELISA kits (IL-1 $\beta$, IL- 6 and IFN- $\gamma$ ) were provided by BD Biosciences (Franklin Lakes, NJ, USA). Fluorescein-5-isothiocyanate (FITC)-labeled Escherichia coli was procured from Gibco (Invitrogen Corporation, Grand Island, NY, USA).

\section{Extraction and Separation of DCP}

The extraction and separation of DCP from fresh $D$. catenatum stem were carried out by TPP and ethanol precipitation method according to a previous study (19) with slight modifications. In brief, the freshly harvested D. catenatum stems (100 g) were washed with tap water, cut into small pieces, added with $500 \mathrm{~mL}$ of distiller water, and pulped twice with a household food processer. After centrifugation $(2,683 \mathrm{~g}, 20 \mathrm{~min})$, the supernatant was mixed with $20 \%$ (w/w) $\left(\mathrm{NH}_{4}\right)_{2} \mathrm{SO}_{4}$, followed by 1.5 volumes of $t$-butanol, and then incubated at $25^{\circ} \mathrm{C}$ for 30 min under continuous stirring. After centrifugation at 2,683 $g$ for $15 \mathrm{~min}$, a clear three phases was formed. The upper phase containing $t$-butanol was recycled by vacuum evaporation. The lower $\left(\mathrm{NH}_{4}\right)_{2} \mathrm{SO}_{4}$ phase was collected, precipitated by fourfold volumes of $95 \%$ ethanol overnight, centrifuged, dissolved, dialyzed (molecular weight cut-off: 3,500 Da), and lyophilized to obtain the DCP solid, which was sealed in an airtight plastic bag and stored at $4^{\circ} \mathrm{C}$ prior to testing. The steps for the extraction and separation of DCP from fresh D. catenatum stems via TPP and ethanol precipitation are graphically depicted in Figure 1.

\section{Structural Characterization of DCP Chemical Component Analysis}

The contents of carbohydrate, uronic acid, and soluble protein in DCP were measured through the assays of phenol-sulfuric acid, carbazole-sulfuric acid, and Bradford by using glucose (Glc), galacturonic acid (GalA), and BSA as standards, respectively (20-22).

\section{Size Exclusion Chromatography Coupled With Multi-Angle Laser Light Scattering and Refractive Index (SEC-MALLS-RI) Analysis}

The SEC-MALLS-RI analysis was used to determine the homogeneity, weight-average molecular weight $\left(M_{w}\right)$, numberaverage molecular weight $\left(M_{n}\right)$, molecular weight distribution $\left(M_{w} / M_{n}\right)$, and $z$-average radius of gyration $\left(R_{z}\right)$ of the DCP. The HPSEC-MALLS-RI system was composed of a Waters 2695 HPLC (Waters, Milford, MA, USA), a MALLS detector (DAWN HELEOS II $\lambda=623.8 \mathrm{~nm}$; Wyatt Technologies Corporation, USA), and a RI detector (Waters) equipped with a guard column (TSK PWXL, Japan) and a TSK G6000 PWXL column $(7.8 \mathrm{~mm} \times$ $30 \mathrm{~cm}$, Japan) at $30^{\circ} \mathrm{C}$. The eluant was $0.05 \mathrm{~mol} / \mathrm{L} \mathrm{NaH}_{2} \mathrm{PO}_{4}$ and $0.15 \mathrm{~mol} / \mathrm{L} \mathrm{NaNO}_{3}$ containing $0.02 \%(w / w) \mathrm{NaN}_{3}(\mathrm{pH} 7.0)$ at the 


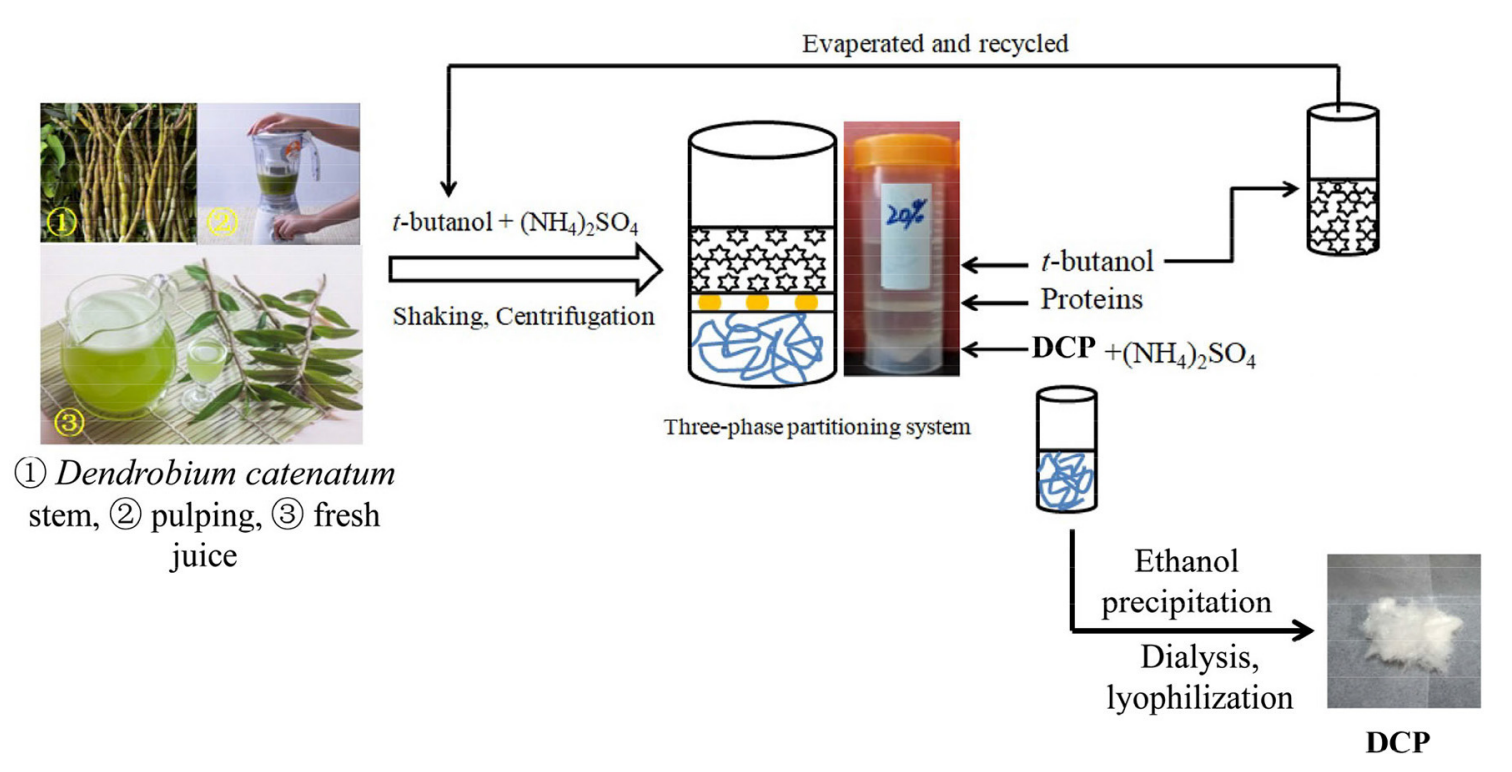

FIGURE 1 | Extraction and isolation procedures for the DCP from fresh D. catenatum stems by using TPP and ethanol precipitation.

flow rate of $0.5 \mathrm{~mL} / \mathrm{min}$. The refractive index increment $(d n / d c)$ value was used as $0.146 \mathrm{~mL} / \mathrm{g}(23)$.

\section{Monosaccharide Composition Analysis}

Following the method of Yan et al. (24), the monosaccharide constituents of the DCP were determined by using an ion chromatography (IC, ICS5000, American Diane Company, CA, USA) equipped with a pulsed amperometric detector (Au electrode) and a Carbopac PA-20 column $(150 \mathrm{~mm} \times 3 \mathrm{~mm})$ at $30^{\circ} \mathrm{C}$. After hydrolysis with $2.0 \mathrm{~mol} / \mathrm{L}$ TFA at $110^{\circ} \mathrm{C}$ for $6 \mathrm{~h}$, the DCP sample was evaporated, diluted, filtered, and detected. The eluant and flow rate were $2.0 \mathrm{mmol} / \mathrm{L}$ $\mathrm{NaOH}$ solution and $0.45 \mathrm{~mL} / \mathrm{min}$, respectively. Glc, mannose (Man), galactose (Gal), rhamnose (Rha), arabinose (Ara), xylose (Xyl), fucose (Fuc), fructose (Fru), glucosamine (GlcN), glucuronic acid (GlcA), and GalA were used as monosaccharide standards and detected in accordance with the procedures described above.

\section{Fourier-Transform Infrared (FT-IR) Spectroscopy}

The lyophilized DCP (1.0 mg) was mixed with $\mathrm{KBr}$ powder at a mass ratio of 1:100 $(w / w)$ and pressed into a $1 \mathrm{~mm}$ transparent flake. The FT-IR spectrum of DCP was then obtained with a FT-IR spectrometer (Nexus 670, Thermo Nicolet Co., USA) varying in the range of $400-4,000 \mathrm{~cm}^{-1}$ with a resolution of $4 \mathrm{~cm}^{-1}$.

\section{Nuclear Magnetic Resonance (NMR) Spectroscopy}

The lyophilized DCP $(30 \mathrm{mg})$ was dissolved in $0.5 \mathrm{~mL}$ of $\mathrm{D}_{2} \mathrm{O}$ to record its $1 \mathrm{D}\left({ }^{1} \mathrm{H}\right.$, and $\left.{ }^{13} \mathrm{C}\right)$ and $2 \mathrm{D}$ [heteronuclear single-quantum correlation spectroscopy (HSQC), and heteronuclear multiple-bond correlation spectroscopy (HMBC)] NMR spectra. The NMR spectra were recorded on a Bruker AVIII-600 NMR instrument (Bruker, Rheinstetten,
Germany) at $25^{\circ} \mathrm{C}$ with tetramethylsilane as an external standard ( $\delta 0.00 \mathrm{ppm})$.

\section{Rheological Analysis of DCP}

The rheological behaviors of DCP at various concentrations (20$60 \mathrm{mg} / \mathrm{mL}$ ) were carried out on a DHR-1 rheogoniometer (TA instruments, New Castle, USA) at $25^{\circ} \mathrm{C}$ according to the method of Cai et al. (25). A cone and plane geometry system of $40 \mathrm{~mm}$ cone diameter, $1^{\circ}$ angle, and $29 \mu \mathrm{m}$ gap was used. The steady shear behavior of the DCP was detected at shear rates ranging from 0.1 to $1,000 \mathrm{~s}^{-1}$. The dynamic viscoelastic behavior of the DCP was investigated by frequency sweep changing from 0.1 to $100 \mathrm{rad} / \mathrm{s}$ at a strain of $2 \%$ within the linear viscoelastic region. Also, storage modulus $\left(G^{\prime}\right)$ and loss modulus $\left(G^{\prime \prime}\right)$ were obtained. Data collection and analysis were performed via the on-line Trios 3.0 software.

\section{In vitro Immunostimulatory Activity of DCP Cell Culture}

RAW264.7 murine macrophages cell line was supplied by American Type Culture Collection (Manassas, VA, USA). The cells were cultured in a dish containing DMEM supplemented with $10 \% \mathrm{FBS}, 100 \mathrm{U} / \mathrm{mL}$ penicillin, and $100 \mu \mathrm{g} / \mathrm{mL}$ streptomycin in a humidified atmosphere of $5 \% \mathrm{CO}_{2}$ at $37^{\circ} \mathrm{C}$.

\section{Cell VIAbility}

Cell viability was inspected using the CCK-8 assay. RAW264.7 cells were seeded in 96-well plates at a density of $5 \times 10^{4}$ cells per well. After $24 \mathrm{~h}$, the cells were incubated with DCP at different concentrations $(25-200 \mu \mathrm{g} / \mathrm{mL})$ for $24 \mathrm{~h}$. After incubation, each well was added with $10 \mu \mathrm{L}$ of CCK- 8 reagent and incubated for $4 \mathrm{~h}$. Absorbance at $450 \mathrm{~nm}$ was recorded on a microplate reader (Biotek, Winooski, VT, USA). 


\section{Assay for Macrophage Phagocytosis}

RAW264.7 cells were seeded in a 96-well plate, incubated at $37^{\circ} \mathrm{C}$ in a humidified atmosphere of $5 \% \mathrm{CO}_{2}$ overnight, and treated with various concentrations $(25-200 \mu \mathrm{g} / \mathrm{mL})$ of DCP and LPS $(4 \mathrm{ng} / \mathrm{mL})$ for $24 \mathrm{~h}$. Afterward, each well was added with 100 $\mu \mathrm{L}$ of FITC-labeled E. coli and incubated at $37^{\circ} \mathrm{C}$ for $2 \mathrm{~h}$. The cells were rinsed twice with PBS to wash away the FITC-labeled bacteria that were not phagocytosed by macrophages, then fixed with $4 \%$ paraformaldehyde, and finally photographed through an inverted microscope (Nikon Corporation, Tokyo, Japan).

\section{Nitrite Assay}

The amount of nitrite, an indicator of NO, was commonly detected by Griess reagent as an indicator of immunoenhancing activity. RAW264.7 cells were plated in 96-well cell culture plates with a density of $5 \times 10^{5}$ cells/well. After $24 \mathrm{~h}$, the cells were treated with DCP $(25-200 \mu \mathrm{g} / \mathrm{mL})$ and LPS $(4 \mathrm{ng} / \mathrm{mL})$ for another $24 \mathrm{~h}$. Nitrite amount was measured using Griess reagent ( $1 \%$ sulfanilamide and $0.1 \%$ naphthylethylenediamine dihydrochloride in $2.5 \%$ phosphoric acid). Each well was added with $100 \mu \mathrm{L}$ of cell culture medium mixed with $100 \mu \mathrm{L}$ of Griess reagent and incubated for $30 \mathrm{~min}$. Absorbance at $540 \mathrm{~nm}$ was measured.

\section{Measurement of Cytokine Expression}

RAW264.7 cells were seeded into a 96-well microplate at $5 \times$ $10^{5}$ cells/well and incubated with or without DCP with the final concentration of $25-200 \mu \mathrm{g} / \mathrm{mL}$. After incubation for $24 \mathrm{~h}$ at $37^{\circ} \mathrm{C}$ in a humidified atmosphere with $5 \% \mathrm{CO}_{2}$, the culture supernatants were harvested for the measurement of cytokine contents (IL-1 $\beta$, IL-6, and IFN- $\gamma$ ) by ELISA kits in accordance with the manufacturer's instructions. Absorbance at $450 \mathrm{~nm}$ was detected.

\section{Statistical Analysis}

All treatments in immunostimulatory activity assay were conducted in triplicate. GraphPad Prism 8 software was used for statistical analysis, and all data were presented as mean \pm SEM. One-way ANOVA and Turkey's multiple comparison was used to analyze differences among groups. A level of $p<0.05$ signified statistical significance and indicated as follows: ${ }^{*} p<0.05,{ }^{* *} p<$ $0.01,{ }^{* * *} p<0.001$.

\section{RESULTS AND DISCUSSIONS \\ Physicochemical Properties and Chain Conformation of DCP}

After TPP and ethanol precipitation, a water-soluble DCP was obtained from fresh $D$. catenatum stems with a yield of $15.2 \% \pm 0.6 \%$ (Figure 1). The chemical composition, molecular parameters, and monosaccharide constituents of the DCP are summarized in Table 1. The contents of total carbohydrate and uronic acid in DCP were $92.75 \% \pm 1.78 \%$ and $5.80 \pm 0.05 \%$, respectively, suggesting that this polysaccharide is acidic with high purity. According to the Bradford method, no protein was detected in the DCP. This finding indicated that TPP combined with ethanol precipitation could effectively remove free proteins in the DCP, and this finding was similar to our earlier research (26). Moreover, no characteristic absorption peaks at $\sim 260$ and $280 \mathrm{~nm}$ were found in the UV-vis spectrum of DCP (data not shown), thus further implying the absence of nucleic acids and protein. As illustrated in Table $\mathbf{1}$ and Figure 2A, the DCP was consisted of Glc and Man with a trace of GalA at a molar ratio of 30.2:69.5:0.3 according to monosaccharide standards. Therefore, Man and Glc were the predominant monosaccharides in the DCP. This outcome revealed that the DCP obtained from fresh D. catenatum stems with TPP and ethanol precipitation was an acidic glucomannan, which was inconsistent with the results reported by $\mathrm{He}$ et al. (27), Kuang et al. (28), and Zhang et al. (10). Liang et al. (29) found that the two polysaccharides (DOP1DES and DOP2-DES) obtained from D. officinale stem via deep eutectic solvents were both mannoglucans comprising by Glc and Man in the percentages of 2.2:1.0 and 3.7:1.0, respectively. This finding was different from the above-mentioned data. Gal and Ara were also found in other reported D. officinale polysaccharides $(30,31)$. These differences in monosaccharide composition were mainly attributed the variation in the sources of $D$. catenatum plant and the preparation protocols.

Figure $3 \mathrm{~A}$ shows that the chromatographic peak of the DCP had a single symmetrical peak, which demonstrated that the DCP obtained from fresh D. catenatum stems through TPP and ethanol precipitation had high homogeneity within the measured molar mass range. Table 1 shows that the $M_{w}, M_{n}$, and $M_{w} / M_{n}$ of the DCP were $2.21 \times 10^{5} \mathrm{Da}, 2.18 \times 10^{5} \mathrm{Da}$, and 1.01, respectively. The $M_{w}$ of DCP was larger than those of previously reported polysaccharides extracted from dried $D$. officinale stems $\left(6.8 \times 10^{3}-1.78 \times 10^{5} \mathrm{Da}\right)(8,28,31-33)$. The DCP with high $M_{w}$ would be beneficial for an enhanced immunostimulatory activity, which was verified in Section

TABLE 1 | Chemical composition, molecular parameters, and monosaccharide constituents of the DCP isolated from fresh $D$. catenatum stems by TPP and ethanol precipitation.

\begin{tabular}{|c|c|c|c|c|c|c|c|c|c|c|c|}
\hline \multirow[t]{2}{*}{ Sample } & \multirow{2}{*}{$\begin{array}{l}\text { Yield } \\
(\%)\end{array}$} & \multirow{2}{*}{$\begin{array}{l}\text { Sugar } \\
\text { (wt\%) }\end{array}$} & \multirow{2}{*}{$\begin{array}{l}\text { Uronic acid } \\
\qquad(w t \%)\end{array}$} & \multirow{2}{*}{$\begin{array}{l}\text { Protein } \\
\text { (wt\%) }\end{array}$} & \multirow{2}{*}{$\begin{array}{c}M_{w} \\
\left(\times 10^{5} \mathrm{Da}\right)\end{array}$} & \multirow{2}{*}{$\begin{array}{c}M_{n} \\
\left(\times 10^{5} \mathrm{Da}\right)\end{array}$} & \multirow[t]{2}{*}{$M_{w} / M_{n}$} & \multirow{2}{*}{$\begin{array}{c}R_{z} \\
(n m)\end{array}$} & \multicolumn{3}{|c|}{ Sugar composition (mol\%) } \\
\hline & & & & & & & & & Glc & Man & GalA \\
\hline DCP & $15.2 \pm 0.6$ & $92.75 \pm 1.78$ & $5.80 \pm 0.05$ & n.d. & 2.21 & 2.18 & 1.01 & 17.9 & 30.2 & 69.5 & 0.3 \\
\hline
\end{tabular}

n.d. not determined. 

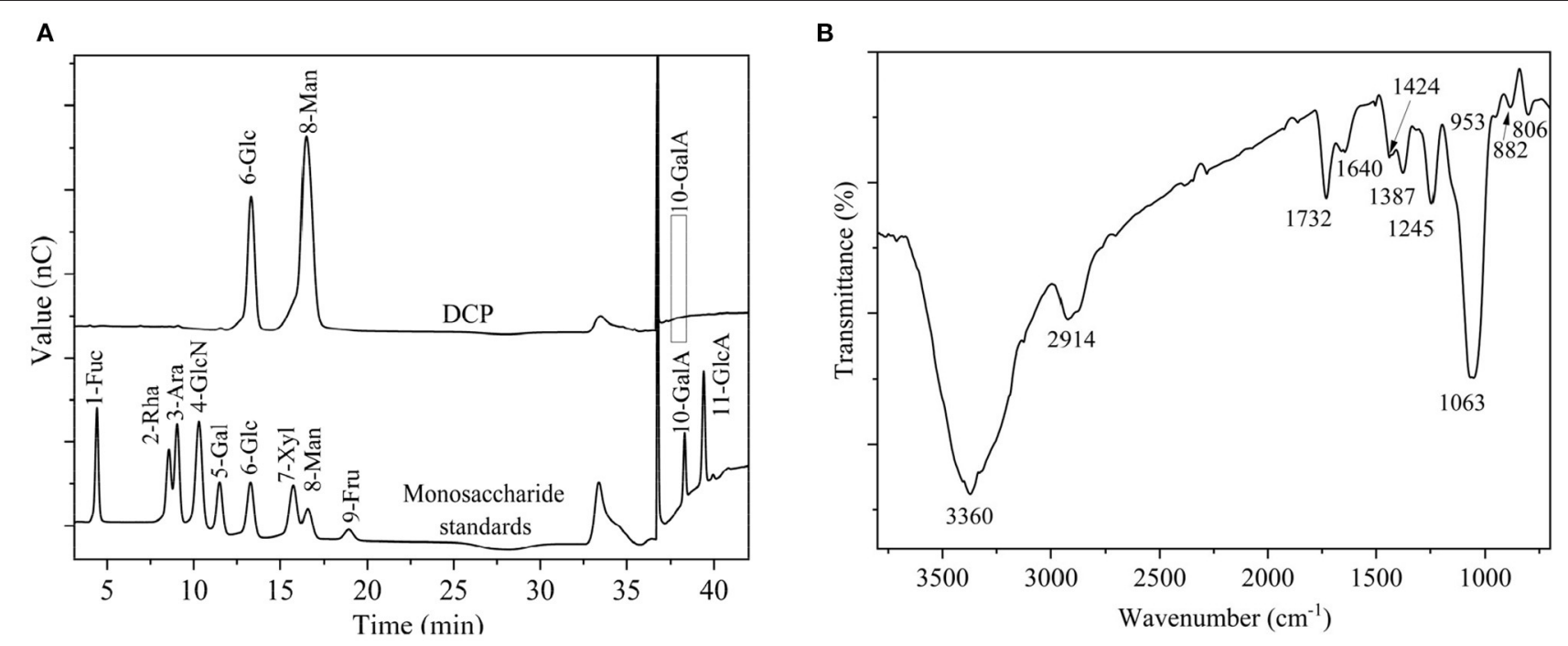

FIGURE 2 | (A) Monosaccharide compositions of DCP and monosaccharide standards, and (B) FT-IR spectrum of DCP.

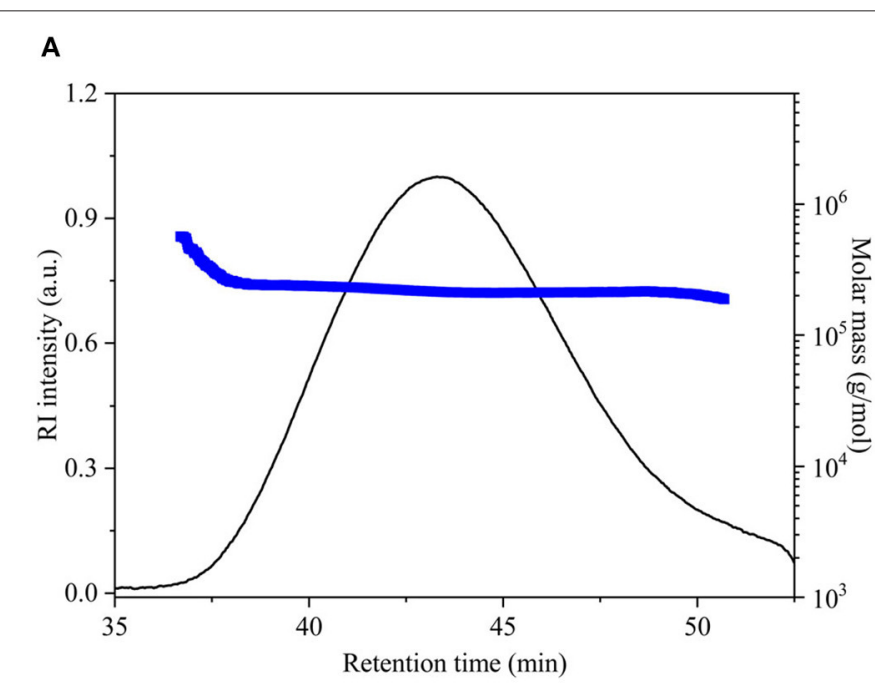

B

FIGURE 3 | (A) SEC elution and molar mass profiles, and (B) logarithmic plot of $M_{w}$ vs. $R_{Z}$ for DCP.

in vitro Immunostimulatory Activity of DCP. In addition, its $M_{w} / M_{n}(1.01)$ value further indicated that the DCP was a highly homogenous polysaccharide.

The chain conformation of polysaccharide in solution can be estimated by the relationship between $M_{w}$ and $R_{z}\left(R_{z}=\right.$ $k \cdot M_{w}^{\alpha}$ ) obtained from the SEC-MALLS-RI analysis (18). In general, the conformational parameter $\alpha$ of $0.3,0.5-0.6$, and $\geq 1.0$ corresponds to the chain conformation of spheres, flexible chains, and rigid rods, respectively. In this work, the logarithmic plot describing the relationship between the $M_{w}$ and $R_{z}\left(R_{z}\right.$ $=k \cdot M_{w}{ }^{\alpha}$ ) of DCP is displayed in Figure 3B. The value of $\alpha$ for DCP was 1.35, which was higher than 1.0, revealing that the DCP presented as an extended rigid rod in aqueous solution ( $\mathrm{pH} 7.0)$.

\section{Structural Features of DCP}

Figure 2B displays the FT-IR spectrum of DCP. The DCP exhibited typical characteristic bands of polysaccharides. The wide and strong stretching vibration band at $\sim 3,360 \mathrm{~cm}^{-1}$ signified the existence of $\mathrm{O}-\mathrm{H}$ group, and the small and feeble stretching vibration at $\sim 2,914 \mathrm{~cm}^{-1}$ corresponded to the C$\mathrm{H}$ group of methyl and methylene groups. The signals at $\sim 1,732$ and $1,640 \mathrm{~cm}^{-1}$ corresponding to stretching vibrations of $\mathrm{C}=\mathrm{O}$ of $\mathrm{O}$-acetyl $\left(-\mathrm{O}-\mathrm{COCH}_{3}\right)$ and carboxylic (COO-) groups, respectively (34). Therefore, the DCP might be an acidic or $\mathrm{O}$ acetylated glucomannan, and this finding was in accord with the findings of Table 1 and previous studies $(32,33,35)$. The peak near $1,424 \mathrm{~cm}^{-1}$ was associated with stretching vibration of the C-O-H group. Signals near 1,387, 1,245, and 1,063 $\mathrm{cm}^{-1}$ 
were separately related to bending vibration of $\mathrm{C}-\mathrm{H}$ group, and stretching vibrations of $\mathrm{C}-\mathrm{O}$ and $\mathrm{C}-\mathrm{O}-\mathrm{C}$ groups. The characteristic absorption peaks at $\sim 953,886$, and $808 \mathrm{~cm}^{-1}$ indicated that the DCP had the $\alpha$ - and $\beta$-configurations of Man and Glc in pyranose sugar forms, respectively (29).

The structural feature of DCP was further characterized by using $1 \mathrm{D}\left({ }^{1} \mathrm{H}\right.$, and $\left.{ }^{13} \mathrm{C}\right)$ and $2 \mathrm{D}$ (HSQC and HMBC) NMR measurement, and the obtained results are illustrated in Figure 4 and Table 2. In the ${ }^{1} \mathrm{H}$ NMR (Figure 4A) and ${ }^{13} \mathrm{C}$ NMR (Figure 4B) spectra, the signals of anomeric protons ( $\mathrm{H}-1)$ and carbons $(\mathrm{C}-1)$ were primarily within the ranges of $\delta 4.69-5.48$ ppm and $\delta$ 97.98-102.69 ppm, respectively. Among which, the strong signal at $\delta 4.79 \mathrm{ppm}$ was attributed to the $\mathrm{HDO}$ of $\mathrm{D}_{2} \mathrm{O}$. This result indicated that both $\alpha$ - and $\beta$-configurations are present in the DCP. As shown in Figure 4A, the signals at $\delta$ 2.07-2.16 ppm in the ${ }^{1} \mathrm{H}$ NMR spectrum corresponded to the $-\mathrm{CH}_{3}$ group of $\mathrm{O}$-acetyl groups. In the ${ }^{13} \mathrm{C} \mathrm{NMR}$ spectrum of DCP (Figure 4B), the signals at $\delta 173.23 \mathrm{ppm}$ and $\delta 20.79(\delta$ 20.53) ppm were separately ascribed to the $-\mathrm{COOH}$ and $-\mathrm{CH}_{3}$ groups of $\mathrm{O}$-acetyl groups. These findings suggested the existence of O-acetyl groups in the DCP, which was in line with the FTIR analysis (Figure 2B) and previously reported data $(33,35)$. The presence of $O$-acetyl groups in DCP might be responsible for the enhanced phagocytic activity of RAW264.7 cells during

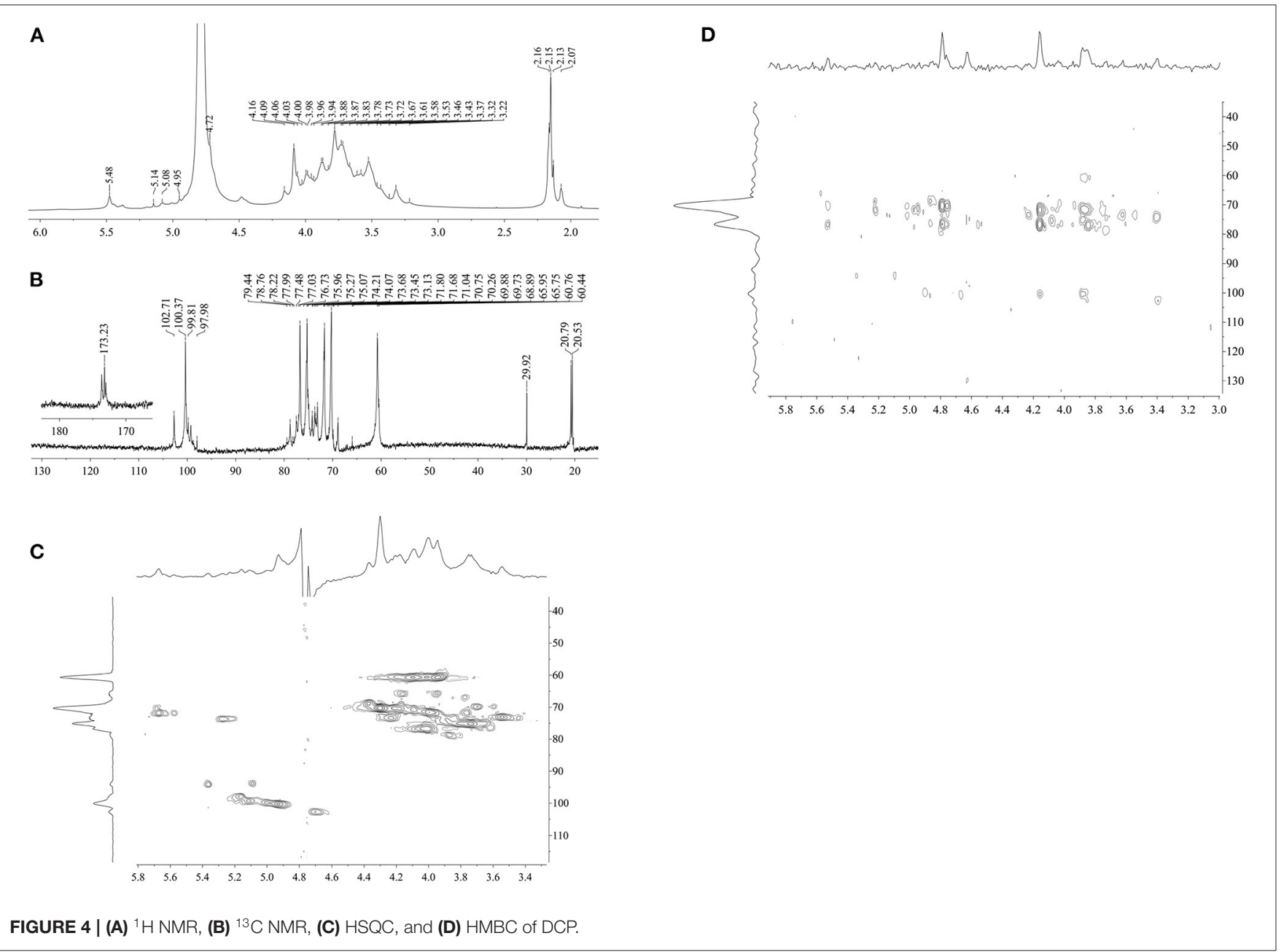

TABLE $2 \mid{ }^{1} \mathrm{H}$ and ${ }^{13} \mathrm{C}$ NMR chemical shift $(\delta$, ppm) assignments for DCP.

\begin{tabular}{|c|c|c|c|c|c|c|}
\hline Sugar residues & \multicolumn{6}{|c|}{ Chemical shifts $(\delta, \mathrm{ppm})$} \\
\hline 2-O-acetyl-(1 $\rightarrow 4)$ - $\beta$-D-Manp & 4.95/100.37 & $5.48 / 71.68$ & $4.06 / 70.75$ & 3.88/75.96 & $3.67 / 75.27$ & $4.00(3.73) / 60.44$ \\
\hline$(1 \rightarrow 6)-\alpha-D-G l c p$ & $5.08 / 99.81$ & $3.53 / 73.68$ & $3.72 / 73.68$ & $3.43 / 73.45$ & $3.94 / 74.07$ & $3.87(3.78) / 65.95$ \\
\hline$(1 \rightarrow 4)-\alpha$-D-Glcp & $5.14 / 97.98$ & $3.58 / 73.13$ & $3.72 / 69.88$ & $3.67 / 75.07$ & $4.16 / 65.75$ & $3.83(3.78) / 60.76$ \\
\hline
\end{tabular}


immunoprotection (34), which was further confirmed in Section In vitro Immunostimulatory Activity of DCP.

The anomeric signals at $\delta 4.72,4.95,5.08$, and $5.14 \mathrm{ppm}$ in the ${ }^{1} \mathrm{H}$ NMR spectrum (Figure 4A) and $\delta 102.71,100.37,99.81$, and $97.98 \mathrm{ppm}$ in the ${ }^{13} \mathrm{C}$ NMR spectrum (Figure 4B) corresponded to the $\mathrm{H}-1 / \mathrm{C}-1$ of $(1 \rightarrow 4)-\beta-\mathrm{D}$-mannopyranosyl (Manp), 2$O$-acetyl-( $1 \rightarrow 4)-\beta$-D-Manp, $(1 \rightarrow 6)$ - $\alpha$-D-glucopyranosyl (Glcp), and $(1 \rightarrow 4)-\alpha$-D-Glcp of DCP, respectively $(8,31,36)$. As displayed in Figure 4A, the signal at $\delta 5.48 \mathrm{ppm}$ belonged to the $\mathrm{H}-2$ of $2-O$-acetyl- $(1 \rightarrow 4)-\beta$-D-Manp. This outcome showed that the DCP comprised four types of sugar residues, which were further identified by HSQC (Figure 4C). No signals were observed at $\delta 82-88 \mathrm{ppm}$ (feature of furanoses) in the ${ }^{13} \mathrm{C} \mathrm{NMR}$ spectrum (Figure 4B), implying that the DCP was dominantly consisted of pyranose sugars (34). All assignments of other proton (H-2 to $\mathrm{H}-6)$ and carbon (C-2 to C-6) signals for the four sugar residues were confirmed and are listed in Table 2 according to HSQC (Figure 4C) and HMBC (Figure 4D) spectra coupled with published data on $D$. officinale polysaccharides $(6,8,28,31,33,35)$. On the basis of these results, the DCP derived from fresh $D$. catenatum stems via TPP and ethanol precipitation was classified as glucomannan and mainly composed of $(1 \rightarrow 4)-\beta$-D-Manp, 2 - $O$-acetyl- $(1 \rightarrow 4)-\beta$-D-Manp, $(1 \rightarrow 6)-\alpha-D-G l c p$, and $(1 \rightarrow 4)-\alpha-D-G l c p$ residues, with Man and Glc as the predominant components.

\section{Rheological Properties of DCP}

Figure 5A illustrates the steady-state fluid behavior of aqueous DCP at $20-60 \mathrm{mg} / \mathrm{mL}$ concentrations and $25^{\circ} \mathrm{C}$. It was noted that the apparent viscosity $\left(\eta_{a}\right)$ of DCP solutions was positively correlated with their concentrations but negatively correlated with the shear rate $(\gamma)$. Figure $5 \mathbf{A}$ shows that the $\eta_{a}$ of DCP decreased with the increase in $\gamma$ within the measured concentration range $(20-60 \mathrm{mg} / \mathrm{mL})$, suggesting that the DCP exhibited a non-Newtonian shear-thinning behavior in aqueous solution. This outcome might be due to the breakage of the entwined polysaccharide chains by shear force (25). Moreover, the shear-thinning nature of DCP was highly evident at low $\gamma\left(0.1-10 \mathrm{~s}^{-1}\right)$. An analogous phenomenon was also reported in okra polysaccharides $(18,37)$ and yeast mannans $(38)$. At a high $\gamma\left(>10 \mathrm{~s}^{-1}\right)$, a near-Newtonian plateau was observed in DCP solutions, thus providing the ability to re-establish the entanglements of the disrupted polysaccharide chains. The shearthinning character of the DCP solution was also quantitatively assessed through the Power-law model $\left(\sigma=k \cdot \gamma^{n}\right)$, where $\sigma, k$, and $n$ are the shear stress $(\mathrm{Pa})$, consistency coefficient (Pa.s), and flow behavior index, respectively. In general, the $n$ values of $0-1.0,1.0$, and $>1.0$ reflect shear-thinning, nearNewtonian fluid, and shear-thickening behaviors, respectively (25). Supplementary Table $\mathbf{S} 1$ shows that the determination coefficients $\left(R^{2}\right)$ were all $>0.99$, which suggested that the Powerlaw model was reliable for describing the shear-thinning behavior of DCP in aqueous solution. The value of $n$ decreased from 0.971 to 0.820 , whereas that of $k$ increased from 0.096 to $1.759 \mathrm{~Pa} . \mathrm{s}$ as the DCP concentration increasing from 20 to $60 \mathrm{mg} / \mathrm{mL}$. In agreement with Figure 5A, these results implied that the DCP solution exhibited pronounced shear-thinning nature with high viscosity at high concentrations.

The dynamic viscoelastic behavior of DCP solution at different concentrations $(20-60 \mathrm{mg} / \mathrm{mL})$ and constant strain levels of $2 \%$ and $25^{\circ} \mathrm{C}$ is shown in Figure 5B. The $G^{\prime}$ and $G^{\prime \prime}$ of the DCP exhibited concentration- and frequency-dependent behavior across the tested angular frequency $(\omega)$ range from 0.1 to $100 \mathrm{rad} / \mathrm{s}$. This outcome was in consistent with the before report of Cai et al. (25). At concentrations $\leq 30 \mathrm{mg} / \mathrm{mL}$, the $G^{\prime \prime}$ was always greater than the $G^{\prime}$ throughout the entire

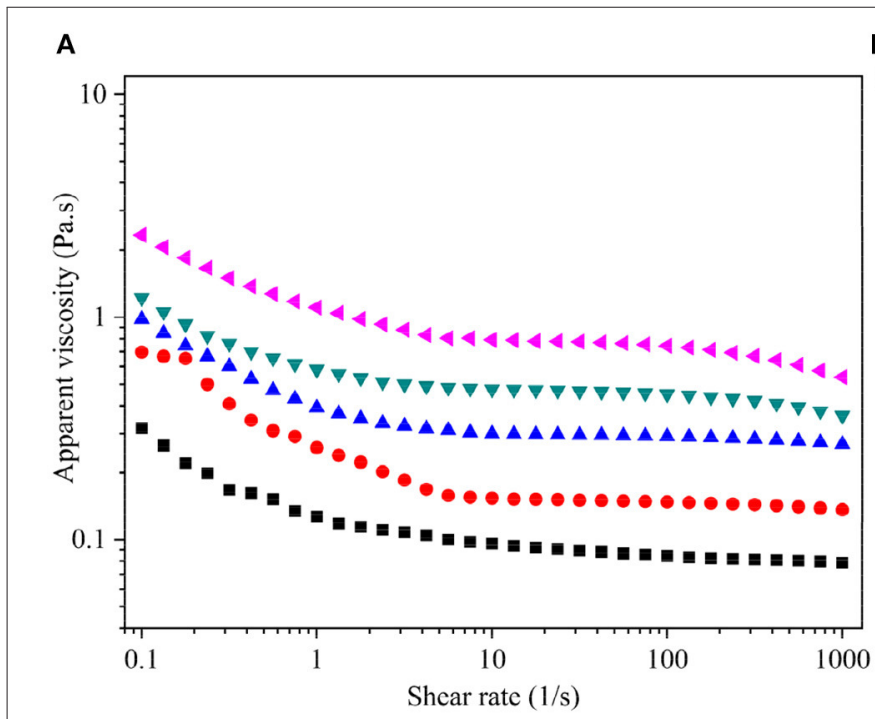

\section{B}

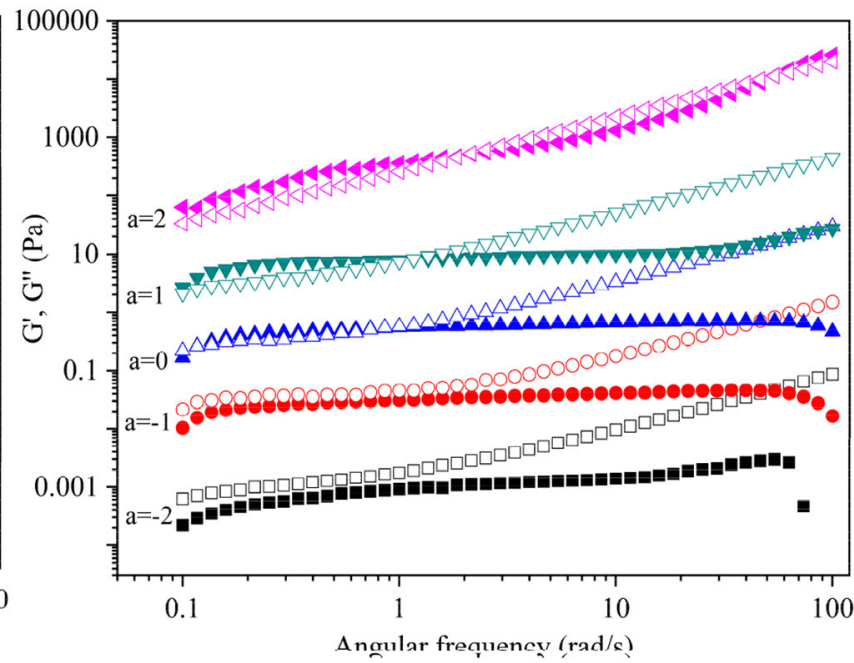

FIGURE 5 | (A) Dependence of apparent viscosity $\left(\eta_{a}\right)$ on shear rate $(\gamma)$, and (B) Plots of storage modulus $G^{\prime}$ (solid symbols) and loss modulus $G^{\prime \prime}$ (open symbols) on angular frequency $(\omega)$ for DCP solution at different concentrations and $25^{\circ} \mathrm{C}$. The DCP concentrations are $20,30,40,50$, and $60 \mathrm{mg} / \mathrm{mL}$ from bottom to top. The data were shifted along vertical axis by $10^{a}$ to avoid overlap. 
range of $\omega$ (Figure 5B), indicating that the DCP predominantly exhibited a fluid-like behavior. At a low $\omega$, the $G^{\prime}$ was almost equal to $G^{\prime \prime}$ with the increasing concentration. At $40 \mathrm{mg} / \mathrm{mL}$, an intercept of $G^{\prime}$ and $G^{\prime \prime}$ was found at low $\omega$, suggesting that the DCP presented viscoelastic property. When the $\omega$ was less than the intercept, that is, $G^{\prime}>G^{\prime \prime}$, the DCP solution showed a solid-like nature. When $\omega$ exceeded the intercept, that is, $G^{\prime}<G^{\prime \prime}$, the DCP solution exhibited a liquid-like nature. Moreover, the intercept of $G^{\prime}$ and $G^{\prime \prime}$ gradually moved to a high $\omega$ as the concentration further increased from 40 to $60 \mathrm{mg} / \mathrm{mL}$ (Figure 5B). This finding indicated that the viscoelastic behavior of DCP solution became evident.

\section{In vitro Immunostimulatory Activity of DCP}

Macrophages are one of the most significant immune cells of the innate immune system and play a substantial role in the body's defense against viral infections (39). These cells produce inflammatory mediators to remove pathogens and repair tissue damage, thereby responding to microbial antigens (40). CCK-8 assay was performed after DCP addition to investigate the effects of DCP on cell viabilities and determine the best concentrations for further studies. As depicted in Figure 6A, the DCP could promote macrophage proliferation. This finding revealed that different concentrations of DCP extracted from fresh D. catenatum stems did not inhibit the growth of
RAW264.7 cells within the measured concentration range (25$200 \mu \mathrm{g} / \mathrm{mL}$ ). Conversely, cell proliferation was induced when the DCP concentration varying from 50 to $200 \mu \mathrm{g} / \mathrm{mL}(p<0.05)$, indicating that the DCP can promote macrophage proliferation. At the same concentration, the ability of DCP to promote cell proliferation was remarkably higher than that reported in literature (34). This finding showed that the DCP with high $M_{w}$ exhibited good immunostimulatory activity. Compared with control group, the DCP obtained from fresh D. catenatum stems (25-200 $\mu \mathrm{g} / \mathrm{mL})$ significantly and dose-dependently upregulated the NO production $(p<0.05)$ (Figure 6B). When the RAW264.7 cells were treated with $200 \mu \mathrm{g} / \mathrm{mL}$ DCP, the NO production reached $13.44 \pm 0.50 \mu \mathrm{M}$, which was higher than those under the treatment of $D$. officinale polysaccharide fractions (DOP1 and DOP-2) reported by Xia et al. (30). These results suggested that DCP could stimulate macrophages to produce inflammatory mediators (e.g., NO) and activate the immune system. Moreover, the tendency of DCP to promote NO secretion was in accord with the outcome of macrophage proliferation (Figure 6A).

Figure 7 displays the immune enhancement effect of DCP on macrophage phagocytosis measured by internalized FITClabeled E. coli particles by using a fluorescence microscope, which can provide visual evidence of phagocytic uptake. One of the main tasks of phagocytes is to detect, engulf, and digest
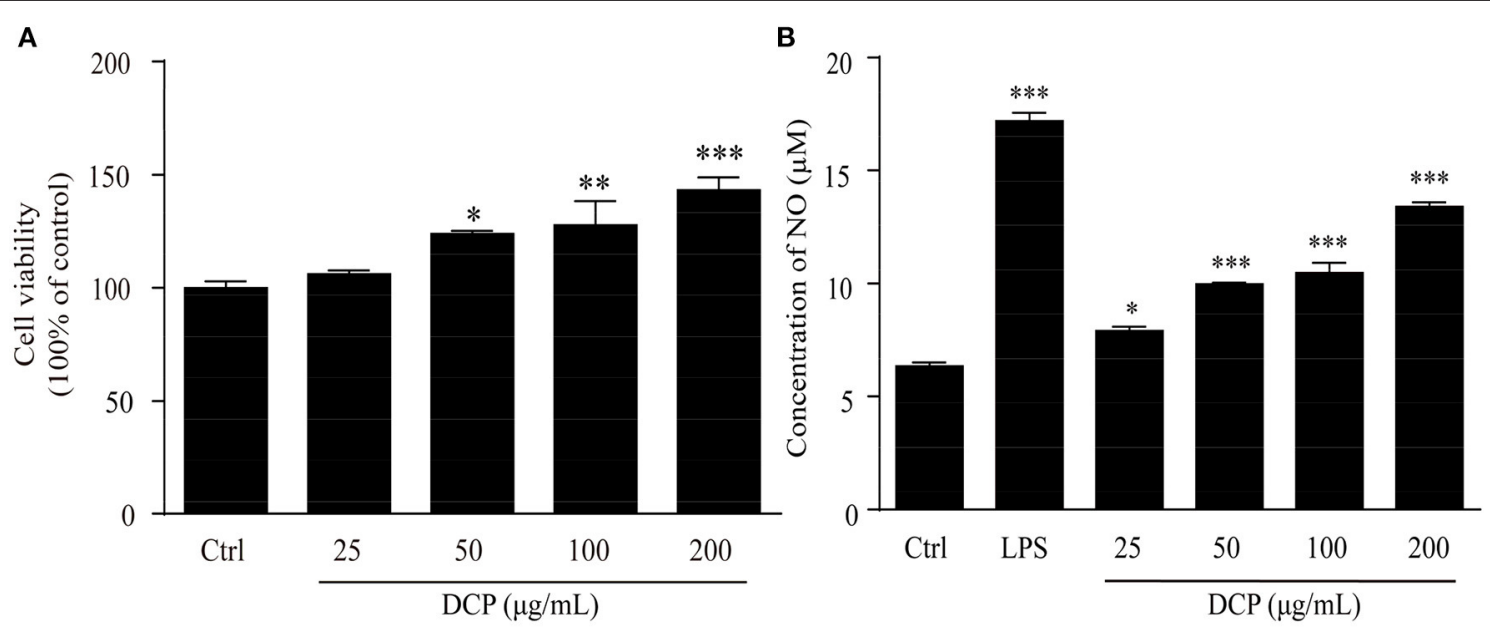

FIGURE 6 | Effect of DCP at different concentrations on $\mathbf{( A )}$ the proliferation of RAW264.7 cells, and (B) NO production in RAW264.7 cells $\left(n=3, \pm\right.$ SEM). ${ }^{*} p<0.05$, ${ }^{\star *} p<0.01,{ }^{* * \star} p<0.001$ vs. the control or LPS group.

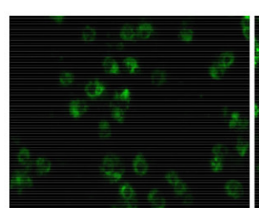

Ctrl

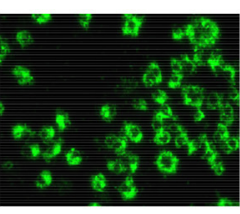

$\operatorname{LPS}(10 \mathrm{ng} / \mathrm{mL})$

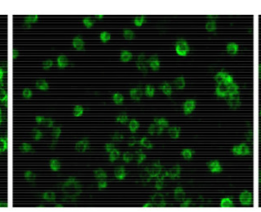

25

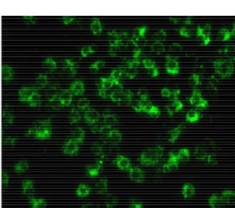

50

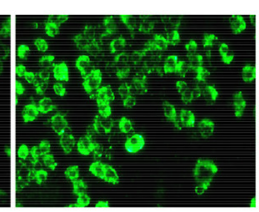

100

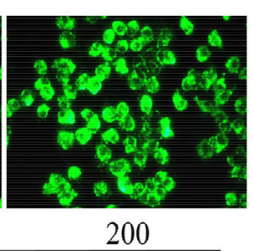

200

$\mathrm{DCP}(\mu \mathrm{g} / \mathrm{mL})$

FIGURE 7 | A fluorescence microscope image of RAW264.7 cells stained with FITC-labeled E. coli ( $\times$ 400). 
foreign objects and apoptotic cell debris by approaching the prey, thus effectively devouring the prey at the highest possible rate (41). Compared with the untreated RAW264.7 macrophages, the cells treated with DCP or LPS for $24 \mathrm{~h}$ showed increased fluorescence intensity after the absorption of FITC-labeled $E$. coli. The RAW264.7 cells treated with $100-200 \mu \mathrm{g} / \mathrm{mL}$ DCP had stronger fluorescence intensity than the LPS-treated cells, especially at $200 \mu \mathrm{g} / \mathrm{mL}$. These data revealed that DCP improved the phagocytic ability and non-specific immunity of RAW264.7 cells within the tested concentration range. Therefore, this polysaccharide can effectively improve the recognition rate of macrophages. Moreover, the fluorescence intensity of RAW264.7 cells treated with DCP in this study was stronger than those of DOP fractions (DOPW-1 and DOPW-2) reported by Tao et al. (6). This finding revealed that the novel DCP exerted more pronounced phagocytic ability compared with DOPW1 and DOPW-2 due to its higher content of $O$-acetyl groups. Therefore, the presence of $O$-acetyl groups may be responsible for the substantially enhanced phagocytic activity of RAW264.7 cells during immune protection.
The effect of DCP on cytokine production is shown in Figure 8. As pro-inflammatory cytokines, IL-6, L-1 $\beta$, and IFN$\gamma$, are critical to the innate immune response of bacteria in cells $(42,43)$. Macrophages primed with IL-6, L- $1 \beta$, and IFN- $\gamma$ rapidly respond to a secondary signal, resulting in their tumoricidal and microbicidal activities that are essential for adaptive immunity against viral and infections $(44,45)$. In this study, the DCP dose-dependently and significantly enhanced the secretion of macrophage-related cytokines, such as IL-6, L-1 $\beta$, and IFN- $\gamma$, in RAW264.7 macrophages within the determined concentration range of $50-200 \mu \mathrm{g} / \mathrm{mL}$ as compared to that in the control group cells $(p<0.05)$. At $200 \mu \mathrm{g} / \mathrm{mL}$, the concentrations of IL-6, L- $1 \beta$, and IFN- $\gamma$ of DCP from RAW264.7 macrophages were $33.89 \pm$ $0.69,100.02 \pm 2.12$, and $1126.04 \pm 18.98 \mathrm{pg} / \mathrm{mL}$, respectively, which were close to those under LPS treatment. This outcome revealed that the DCP effectively stimulated the secretion of cytokines, which in turn activated the macrophages. Xia et al. (30) found that the IL-1 $\beta$ production rate in RAW264.7 cells treated with $200 \mu \mathrm{g} / \mathrm{mL}$ DOP-1 and DOP-2 was within $81.1 \pm 0.8$ and $90.0 \pm 2.2 \mathrm{pg} / \mathrm{mL}$, respectively, which was lower the present result

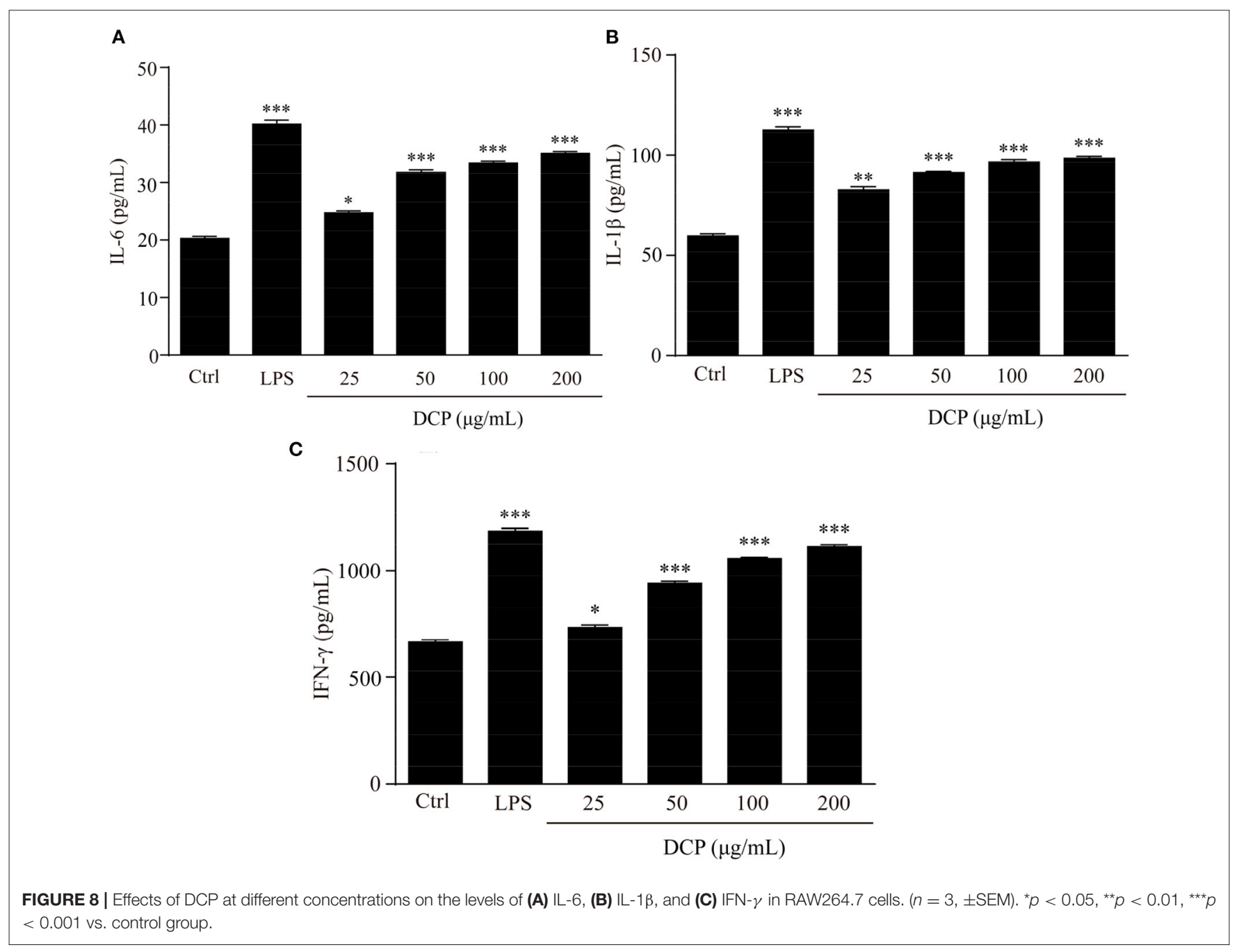


for IL-1 $\beta$ secretion. Therefore, the DCP could help RAW264.7 release cytokines and enhance the body's immune activity.

\section{CONCLUSIONS}

In summary, the present study demonstrated that a novel immunostimulating polysaccharide DCP was obtained from freshly harvested $D$. catenatum stems through TPP coupled with ethanol precipitation. The DCP was an acidic $O$-acetylated glucomannan and comprised by Glc, Man, and GalA in the molar ratio of 30.2:69.5:0.3 with an $M_{w}$ of $2.21 \times 10^{5} \mathrm{Da}$, and existed as an extended rigid rod in aqueous solution with good steadystate fluid and dynamic viscoelastic properties. DCP exhibited beneficial effects on immunostimulation in RAW264.7 cells by promoting macrophage proliferation and NO production, enhancing phagocytic activity and stimulating cytokines secretion. Therefore, the DCP obtained from fresh D. catenatum stems can be developed as a potential immunostimulator for functional food, medicine, and cosmetics uses.

\section{DATA AVAILABILITY STATEMENT}

The raw data supporting the conclusions of this article will be made available by the authors, without undue reservation.

\section{REFERENCES}

1. Si J, Zhang Y, Luo Y, Liu J. Herbal textual research on relationship between Chinese medicine "Shihu" (Dendrobium spp.) and "Tiepi Shihu" (D. catenatum). China. J Chin Materia Medica. (2017) 42:2001-5. doi: 10.19540/j.cnki.cjcmm.20170415.002

2. Editorial Committee of Flora of China YQ. Flora of China. (1999). Beijing: Science Press.

3. Ng TB, Liu J, Wong JH, Ye X, Sze SCW, Tong Y. Review of research on Dendrobium, a prized folk medicine. Appl Microbiol Biotechnol. (2012) 93:1795-803. doi: 10.1007/s00253-011-3829-7

4. Ja TDS, Ng TB. The medicinal and pharmaceutical importance of Dendrobium species. Appl Microbiol Biotechnol. (2017) 101:1-13. doi: 10.1007/s00253-017-8169-9

5. Cheng J, Dang PP, Zhao Z, Yuan LC, Zhou ZH, Wolf D. An assessment of the Chinese medicinal Dendrobium industry: supply, demand and sustainability. J Ethnopharmacol. (2019) 229:81-8. doi: 10.1016/j.jep.2018.09.001

6. Tao S, Lei Z, Huang K, Li Y, Ren Z, Zhang X. Structural characterization and immunodulatory activity of two novel polysaccharides derived from the stem of Dendrobium officinale Kimura et Migo. J Funct Foods. (2019) 57:121-34. doi: 10.1016/j.jff.2019.04.013

7. Liang J, Li H, Chen J, He L, Du X, Zhou L. Dendrobium officinale polysaccharides alleviate colon tumorigenesis via restoring intestinal barrier function and enhancing anti-tumor immune response. Pharmacol Res. (2019) 148:104417. doi: 10.1016/j.phrs.2019.104417

8. Luo Q, Tang Z, Zhang X, Zhong Y, Yao S, Wang L. Chemical properties and antioxidant activity of a water-soluble polysaccharide from Dendrobium officinale. Int $J$ Biol Macromol. (2016) 89:219-27. doi: 10.1016/j.ijbiomac.2016.04.067

9. Liu Y, Yang L, Zhang Y, Liu X, Wu Z, Gilbert RG. Dendrobium officinale polysaccharide ameliorates diabetic hepatic glucose metabolism via glucagon-mediated signaling pathways and modifying liver-glycogen structure. J Ethnopharmacol. (2020) 248:112308. doi: 10.1016/j.jep.2019. 112308

10. Zhang Y, Wu Z, Liu J, Zheng Z, Li Q, Wang H. Identification of the core active structure of a Dendrobium officinale polysaccharide and its protective effect

\section{AUTHOR CONTRIBUTIONS}

JL, LY, JS, YZ, LZ, and JY: designed the experiments. LY, CW, JL, and HX: performed the experiments. JL, LY, and JY: analyzed the data and wrote the manuscript. JY and LZ: reviewed the manuscript. All authors contributed to the article and approved the submitted version.

\section{FUNDING}

This work was supported financially by the National Key R\&D Program of China (2017YFC1702201), the National Natural Science Foundation of China (31671812, 31970316, 32170274), Shanghai Academic Research Leader (19XD1405000), and Opening Foundation of the State Key Laboratory of Subtropical Silviculture, Zhejiang A\&F University (Grant no. 2018FR003, ZY20180206).

\section{SUPPLEMENTARY MATERIAL}

The Supplementary Material for this article can be found online at: https://www.frontiersin.org/articles/10.3389/fnut.2021. 823803/full\#supplementary-material

against dextran sulfate sodium-induced colitis via alleviating gut microbiota dysbiosis. Food Res Int. (2020) 137:109641. doi: 10.1016/j.foodres.2020.109641

11. Yang K, Zhan L, Lu T, Zhou C, Chen X, Dong Y. Dendrobium officnale polysaccharides protected against ethanol-induced acute liver injury in vivo and in vitro via the TLR4/NF-кB signaling pathway. Cytokine. (2020) 130:155058. doi: 10.1016/j.cyto.2020.155058

12. Zhang J, Guo Y, Si J, Sun X, Sun G. A polysaccharide of Dendrobium officinale ameliorates $\mathrm{H}[[\mathrm{sb}]] 2[[/ \mathrm{s}]] \mathrm{O}[[\mathrm{sb}]] 2[[/ \mathrm{s}]]$-induced apoptosis in $\mathrm{H} 9 \mathrm{c} 2$ cardiomyocytes via PI3K/AKT and MAPK pathways. Int J Biol Macromol. (2017) 104:10-10. doi: 10.1016/j.ijbiomac.2017.05.169

13. Fu Y, Zhang J, Chen $\mathrm{K}$, Xiao $\mathrm{C}$, Fan L, Zhang B. An in vitro fermentation study on the effects of Dendrobium officinale polysaccharides on human intestinal microbiota from fecal microbiota transplantation donors. J Funct Foods. (2019) 53:44-53. doi: 10.1016/j.jff.2018. 12.005

14. Guo L, Qi J, Du D, Liu Y. Current advances of Dendrobium officinale polysaccharides in dermatology: a literature review. Pharm Biol. (2020) 58:664-73. doi: 10.1080/13880209.2020.1787470

15. Xing X, Cui SW, Nie S, Phillips GO, Goff HD. A review of isolation process, structural characteristics, and bioactivities of water-soluble polysaccharides from Dendrobium plants. Bioactive Carbohydr Dietary Fibre. (2013) 1:13147. doi: 10.1016/j.bcdf.2013.04.001

16. Yue H, Zeng H, Ding K. A review of isolation methods, structure features and bioactivities of polysaccharides from Dendrobium species. Chin J Nat Med. (2020) 18:1-27. doi: 10.1016/S1875-5364(20)30001-7

17. Yan JK, Wang YY, Qiu WY, Ma H, Wang ZB. Three-phase partitioning as an elegant and versatile platform applied to nonchromatographic bioseparation process. Crit Rev Food Sci Nutr. (2018) 58:2416-31. doi: 10.1080/10408398.2017.1327418

18. Wang $\mathrm{C}$, Yu YB, Chen $\mathrm{TT}$, Wang ZW. Innovative preparation. Physicochemical characteristics and functional properties of bioactive polysaccharides from fresh okra (Abelmoschus esculentus (L) Moench). Food Chem. (2020) 320:126647. doi: 10.1016/j.foodchem.2020.126647

19. Yan JK, Wang C, Yu YB, Wu LX, Chen TT. Physicochemical characteristics and in vitro biological activities of polysaccharides from raw garlic (Allium sativum L.) bulbs via three-phase partitioning combined 
with gradient ethanol precipitation method. Food Chem. (2021) 339:128081. doi: 10.1016/j.foodchem.2020.128081

20. Bitter T, Muir HM. A modified uronic acid carbazole reaction. Anal Biochem. (1962) 4:330-4. doi: 10.1016/0003-2697(62)90095-7

21. Bradford M. A rapid and sensitive method for the quantitation of microgram quantities of protein utilizing the principle of protein-dye binding. Anal Biochem. (1976) 72:248-54. doi: 10.1016/0003-2697(76)90527-3

22. Dubois M, Gilles KA, Hamilton JK, Rebers PA. Calorimetric method for determination of sugars and related substances. Anal Chem. (1956) 28:35066. doi: 10.1021/ac60111a017

23. Morris GA, de al Torre JG, Ortega A, Castile J, Smith A, Harding SE. Molecular flexibility of citrus pectins by combined sedimentation and viscosity analysis. Food Hydrocolloids. (2008) 22:1435-42. doi: 10.1016/j.foodhyd.2007.09.005

24. Yan JK, Wu LX, Qiao ZR, Cai WD. Effect of different drying methods on the product quality and bioactive polysaccharides of bitter gourd (Momordica charantia L.) slices. Food Chem. (2019) 271:588-96. doi: 10.1016/j.foodchem.2018.08.012

25. Cai WD, Qiu WY, Ding ZC, Wu LX. Conformational and rheological properties of a quaternary ammonium salt of curdlan. Food Chem. (2019) 280:130-8. doi: 10.1016/j.foodchem.2018.12.059

26. Wang YY, Ma H, Ding ZC, Yang Y, Wang WH, Zhang HN. Threephase partitioning for the direct extraction and separation of bioactive exopolysaccharides from the cultured broth of Phellinus baumii. Int J Biol Macromol. (2019) 123:201-9. doi: 10.1016/j.ijbiomac.2018.11.065

27. He L, Yan X, Liang J, Li S, He H, Xiong Q. Comparison of different extraction methods for polysaccharides from Dendrobium officinale stem. Carbohydr Polym. (2018) 198:101-8. doi: 10.1016/j.carbpol.2018.06.073

28. Kuang MT, Li JY, Yang XB, Yang L, Xu JY, Yan S. Structural characterization and hypoglycemic effect via stimulating glucagon-like peptide-1 secretion of two polysaccharides from Dendrobium officinale. Carbohydr Polym. (2020) 241:116326. doi: 10.1016/j.carbpol.2020.116326

29. Liang J, Zeng Y, Wang H. Extraction, purification and antioxidant activity of novel polysaccharides from Dendrobium officinale by deep eutectic solvents. Nat Prod Res. (2018) 33:3248-53. doi: 10.1080/14786419.2018.1471480

30. Xia L, Liu X, Guo H, Zhang H, Zhu J. Partial characterization and immunomodulatory activity of polysaccharides from the stem of Dendrobium officinale (Tiepishihu) in vitro. J Funct Foods. (2012) 4:294301. doi: 10.1016/j.jff.2011.12.006

31. Zeng YJ, Yang HR, Wang HF, Zong MH. Immune enhancement activity of a novel polysaccharide produced by Dendrobium officinale edndophytic fungus Fusarium solani DO7. J Funct Foods. (2019) 53:266-75. doi: 10.1016/j.jff.2018.12.038

32. He TB, Huang YP, Yang L, Liu TT, Gong WY, Wang XJ. Structural characterization and immunomodulating activity of polysaccharide from Dendrobium officinale. Int J Biol Macromol. (2016) 83:34-41. doi: 10.1016/j.ijbiomac.2015.11.038

33. Hua YF, Zhang M, Fu CX, Chen ZH. Structural characterization of a 2-Oacetylglucomannan from Dendrobium officinale stem. Carbohydr Res. (2004) 339:2219-24. doi: 10.1016/j.carres.2004.05.034

34. Tian W, Dai L, Lu S, Luo Z, Qiu Z, Li J. Effect of Bacillus sp. DU-106 fermentation on Dendrobium officinale polysaccharide: Structure and immunoregulatory activities. Int J Biol Macromol. (2019) 135:103442. doi: 10.1016/j.ijbiomac.2019.05.203

35. Xing X, Cui SW, Nie S, Phillips GO, Goff HD. Study on Dendrobium officinale O-acetyl-glucomannan (Dendronan $\AA$ ): Part II. Fine structures of O-acetylated residues. Carbohydr Polym. (2015) 117:422-33. doi: 10.1016/j.carbpol.2014.08.121
36. Yang K, Lu T, Zhan L, Zhou C, Zhang N, Lei S. Physicochemical characterization of polysaccharide from the leaf of Dendrobium officinale and effect on LPS induced damage in GES-1 cell. Int J Biol Macromol. (2020) 149:320-30. doi: 10.1016/j.ijbiomac.2020.01.026

37. Wu DT, He Y, Fu MX, Gan RY, Hu YC, Peng LX. Structural characteristics and biological activities of a pectic-polysaccharide from okra affected by ultrasound assisted metal-free Fenton reaction. Food Hydrocoll. (2022) 122:1077085. doi: 10.1016/j.foodhyd.2021. 107085

38. Liu H, Li Y, Shi A, Hu H, Sheng X, Liu L. Rheological characteristics and chain conformation of mannans obtained from Saccharomyces cerevisiae. Int J Biol Macromol. (2018) 107:2404-11. doi: 10.1016/j.ijbiomac.2017. 10.126

39. Keeley T, Costanzo-Garvey DL, Cook LM. Unmasking the many faces of tumor-associated neutrophils and macrophages: Considerations for targeting innate immune cells in cancer. Trends in Cancer. (2019) 5:78998. doi: 10.1016/j.trecan.2019.10.013

40. Louie DAP. Lymph node subcapsular sinus macrophages as the frontline of lymphatic immune defense. Front Immunol. (2019) 10:347. doi: 10.3389/fimmu.2019.00347

41. Jain N, Moeller J. Mechanobiology of macrophages: how physical factors coregulate macrophage plasticity and phagocytosis. Annu Rev Biomed Eng. (2019) 21:267-97. doi: 10.1146/annurev-bioeng-062117-121224

42. Xu H, Jiang $\mathrm{Y}, \mathrm{Xu} \mathrm{X}, \mathrm{Su} \mathrm{X}$, Liu Y, Ma Y. Inducible degradation of lncRNA Srosl promotes IFN- $\gamma$-mediated activation of innate immune responses by stabilizing Stat1 mRNA. Nat Immunol. (2019) 20:162130. doi: 10.1038/s41590-019-0542-7

43. Wu F, Zhou C, Zhou D, Ou S, Liu Z. Immune-enhancing activities of chondroitin sulfate in murine macrophage RAW 2647 cells. Carbohydr Polym. (2018) 198:611-9. doi: 10.1016/j.carbpol.2018. 06.071

44. Li R, Qin X, Liu S, Zhang X, Zeng X, Guo H. [HNMP]HSO[[sb]]4[[/s]] catalyzed synthesis of selenized polysaccharide and its immunomodulatory effect on RAW264.7 cells via MAPKs pathway. Int J Biol Macromol. (2020) 160:1066-77. doi: 10.1016/j.ijbiomac.2020.05.261

45. Wu DT, Feng KL, Huang L, Gan RY, Hu YC. Deep eutectic solvent-assisted extraction, partially structural characterization, and bioactivities of acidic polysaccharides from lotus leaves. Foods. (2021) 10:2330. doi: 10.3390/foods10102330

Conflict of Interest: The authors declare that the research was conducted in the absence of any commercial or financial relationships that could be construed as a potential conflict of interest.

Publisher's Note: All claims expressed in this article are solely those of the authors and do not necessarily represent those of their affiliated organizations, or those of the publisher, the editors and the reviewers. Any product that may be evaluated in this article, or claim that may be made by its manufacturer, is not guaranteed or endorsed by the publisher.

Copyright (c) $2022 \mathrm{Liu}, \mathrm{Yu}$, Wang, Zhang, Xi, Si, Zhang and Yan. This is an openaccess article distributed under the terms of the Creative Commons Attribution License (CC BY). The use, distribution or reproduction in other forums is permitted, provided the original author(s) and the copyright owner(s) are credited and that the original publication in this journal is cited, in accordance with accepted academic practice. No use, distribution or reproduction is permitted which does not comply with these terms. 